\title{
Too many patients with cancer die in acute care hospitals despite palliative options: report
}

A lmost half of all adult cancer deaths in Canada - 45\% -

happen in acute care hospitals, although many people would have benefited from palliative care at home or in hospices, states a report from the Canadian Institute for Health Information.

The institute's End-of-Life Hospital Care for Cancer Patients examined hospital data for 25114 cancer patients from all provinces except Quebec. The study reviewed the final 28 days of patients aged 20 or older, and found palliative care was the main reason $53 \%$ of all patients with cancer were in hospital. But acute care hospitals are not generally designed to provide the specialized care required by patients who are terminally ill with cancer, the report points out.

The report also found a wide variance in the percentage of people with cancer who died in acute care settings, depending upon the province in which they died. The likelihood of a patient with terminal cancer dying in hospital was 39\% in British Columbia and 40\% in Ontario, for example, compared to $66 \%$ in New Brunswick and 69\% in Manitoba. The report's authors speculate that palliative care at home or in hospices is more available in provinces with a greater percentage of the population living in urban settings, such as Ontario and British Columbia.

Differences among provinces also reflect different types of hospital care, says Kathleen Morris, the institute's director of system analysis and emerging issues. Palliative units exist in most Manitoba hospitals, for example, and the study's data did not specify what units patients were admitted to when they died.

Overall, the report "points to a mismatch between what cancer patients say they want - to die at home or in a homelike setting - and what actually happens," says Morris.

Cancer is the leading cause of death for Canadians. About one-third of all

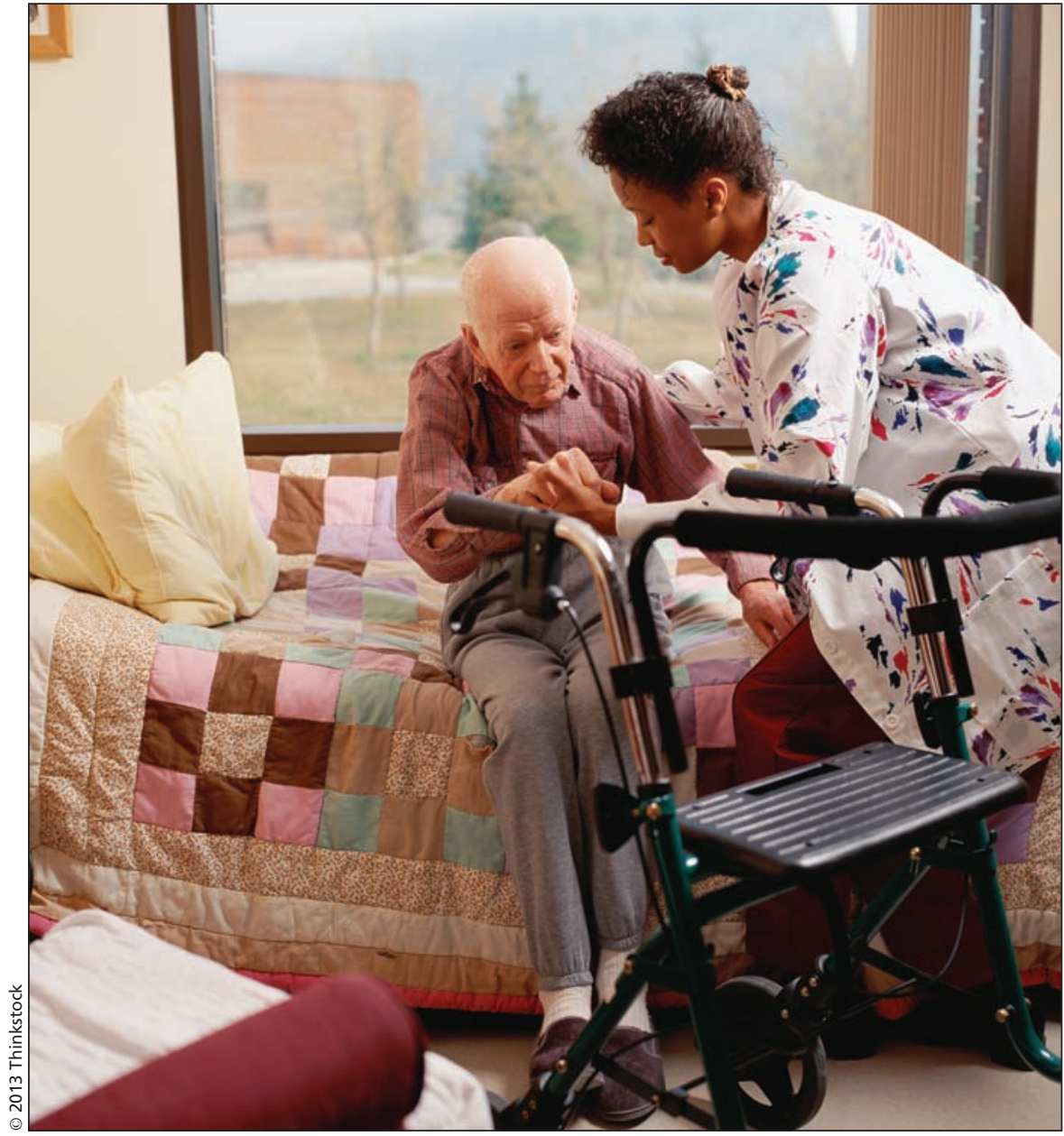

Many patients are dying in acute care hospitals, but palliative care programs could better meet their wishes to die at home or in hospices, says the Canadian Institute for Health Information.

deaths, or an estimated 75700 , were attributed to cancer in 2012.

The report found that one in five patients with cancer admitted to hospital stayed for more than 28 days, providing enough time for patients and their families to plan alternative arrangements like in-home or hospice care, if it was available.

The report does contain some good news about patient care, says Morris. Unlike past practice, acute care hospitals are not subjecting patients to overly aggressive treatment in their last weeks of life.
"We're seeing some really encouraging news about what happens to patients when they're in hospital," Morris says. "Many worry it's a very high-tech, inhuman end of life. We looked for clues of that, and saw that only about one in 10 cancer patients were in the [intensive care unit] during last few weeks."

Additionally, only $3 \%$ of patients with cancer received chemotherapy in the last two weeks of life. Those who did were usually not diagnosed as palliative. Considering chemotherapy's severe adverse effects, most experts 
disagree with giving it to patients with a palliative diagnosis.

Morris hopes the report will help open more palliative care options so people have more control over where and how they spend their final days. She also hopes it will prompt more "good, frank discussions" about what patients want at the end of life.

The report only examined patients with cancer, "so we're only speaking about one significant aspect of the palliative field," says Dr. Michael Downing, Victoria Hospice Society's director of research and development. "It would be invaluable to repeat or compare a study of non-cancer palliative patients."

The report contains information that should help create a better palliative care system, says Lee Fairclough, vicepresident of the Canadian Partnership Against Cancer, a federally funded organization that works to implement Canada's cancer control strategy.

"We are working to better prepare families, patients, and caregivers, and support them in making more choices. From our perspective, this is an important set of data that promotes a good conversation," Fairclough says. Catherine Cross, Ottawa, Ont.

CMAJ 2013. DOI:10.1503/cmaj.109-4500 